\title{
MALIGNANT MELANOMA OF THE ORAL CAVITY
}

Vishnu Prasad K. P1, Panduranga Mulky Kamath², Vijendra Shenoy³, Raghavendra Rao 4 , Jayakrishna Anne 5

${ }_{1}^{1}$ Senior Resident, Department of ENT, KMC Hospital, Mangalore, Manipal University.

2 Professor, Department of ENT, KMC Hospital, Mangalore, Manipal University.

${ }^{3}$ Associate Professor, Department of ENT, KMC Hospital, Mangalore, Manipal University.

${ }^{4}$ Associate Professor, Department of ENT, KMC Hospital, Mangalore, Manipal University.

5Junior Resident, Department of ENT, KMC Hospital, Mangalore, Manipal University.

\section{ABSTRACT}

Oral malignant melanoma is a rare aggressive neoplasm commonly affects males and is more frequently seen at the level of the hard palate and gingiva. In many cases, melanoma has evolved from the pre-existing pigmented lesions. These neoplasms are biologically aggressive, but they often go unnoticed since they usually present merely as a hyperpigmented patch on the gingival surface. Performing biopsies of doubtful pigmented lesions helps in early treatment and better prognosis. The surgical excision combined with the chemotherapy is the treatment of choice. Here, we report a rare case of an elderly male patient with oral malignant melanoma with metastasis to vertebral column.

\section{KEYWORDS}

Malignant Melanoma, Oral Cavity, Metastasis, Vertebral Column, Gingiva, Lips, Hard Palate.

HOW TO CITE THIS ARTICLE: Vishnu Prasad KP, Kamath PM, Shenoy V, et al. Malignant melanoma of the oral cavity. J. Evolution Med. Dent. Sci. 2016;5(17):890-892, DOI: 10.14260/jemds/2016/205

\section{INTRODUCTION}

Melanoma is a malignant tumour arising from the neural crest cells.[1] Primary malignant melanoma of the oral cavity is a very rare tumour that arises from the uncontrolled growth of melanocytes in the basal layer of mucosa. ${ }^{[2,3]}$ It is most commonly seen in sixth decade of life, although can be seen at any time after 30 years of age. ${ }^{[4]}$ It is a more frequent finding in people with higher melanin content like Blacks, Japanese and Indians. [5] Alveolar gingivae, palatal mucosa where the tumour is most commonly seen (80\%), other sites include mandibular gingiva, retromolar trigone, buccal mucosa and floor of mouth.[6] Clinical diagnosis can be made out easily as the tumour is pigmented and irregular. In the initial stages the tumour is asymptomatic, but delayed detection has poor prognosis.

\section{CASE REPORT}

A 60-year elderly male came with swelling in the anterior aspect of upper gums since 3 months along with pain for the last 2 weeks. He also noticed a diffuse swelling below the jaw on both sides, which has developed after the intraoral swelling. He is a chronic smoker and consumes alcohol daily for the last 40 years. On examination of the oral cavity, there is a large greyish black mass of size $8 x 4 \mathrm{~cm}$ on the gingival aspect of the upper jaw extending from the gingiva over the right lateral incisor to the left canine with well-defined margins. Superiorly, the lesion was involving the upper gingivolabial sulcus which is shown in Figure 1.

Financial or Other, Competing Interest: None.

Submission 15-01-2016, Peer Review 10-02-2016,

Acceptance 16-02-2016, Published 29-02-2016.

Corresponding Author:

Dr. Vishnu Prasad K. P.

Senior Resident

Department of ENT, KMC Hospital,

Manipal University, Mangalore.

E-mail:dr.vishnukp@yahoo.com

DOI: $10.14260 /$ jemds $/ 2016 / 205$

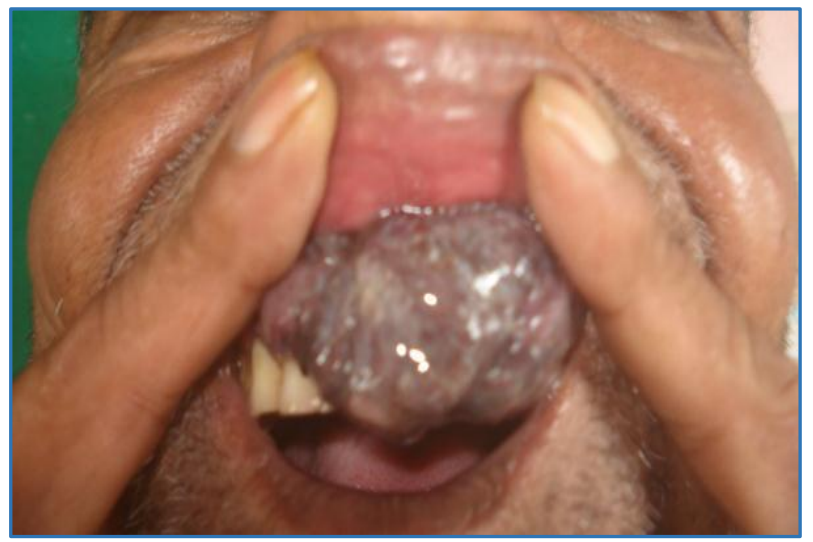

Fig. 1: Mass over the Gingivolabial Sulcus

On palpation of the lesion it was firm in consistency, minimally tender with restricted mobility. Over the neck there was a $4 \times 3 \mathrm{~cm}$ firm, non-tender lymph nodes in bilateral submandibular region along with multiple sub-centimeter lymph nodes in bilateral level II, III and right level IV. Ultrasonography of the neck was performed. It showed enlarged bilateral level IB lymph nodes with necrosis along with above mentioned nodes. Contrast Enhanced Computed Tomography of the oral cavity and neck showed heterogeneously enhancing mass lesion eroding the alveolar process of upper jaw in the region of lateral incisor suggestive of malignancy. Ultrasonography of the abdomen, chest X-ray and 2D echocardiography were normal. Histopathological examination of the lesion reported as malignant melanoma, which is shown in Figure 2. 


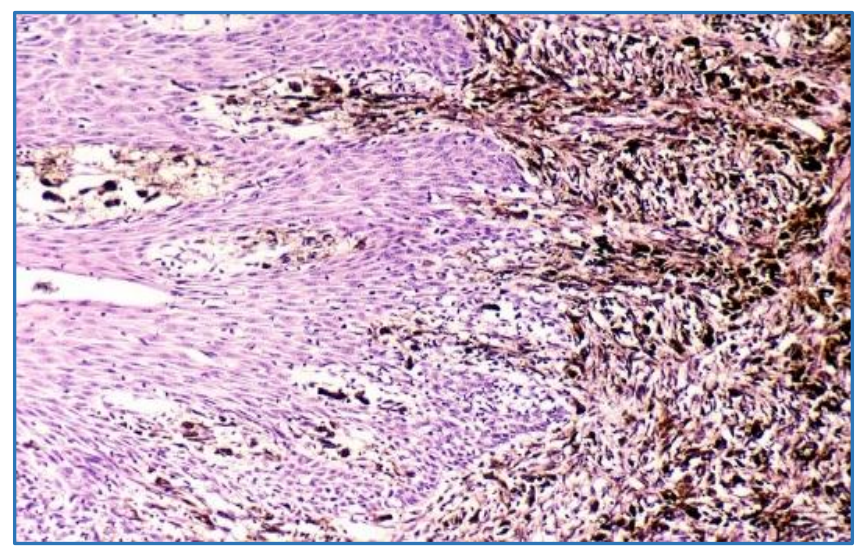

Fig. 2: Histopathology of Malignant Melanoma

A whole body 99m Tc-Methylene Diphosphonate (MDP) bone scan was performed. There was an increased uptake over T10 vertebra suggestive of metastasis shown in Figure 3.

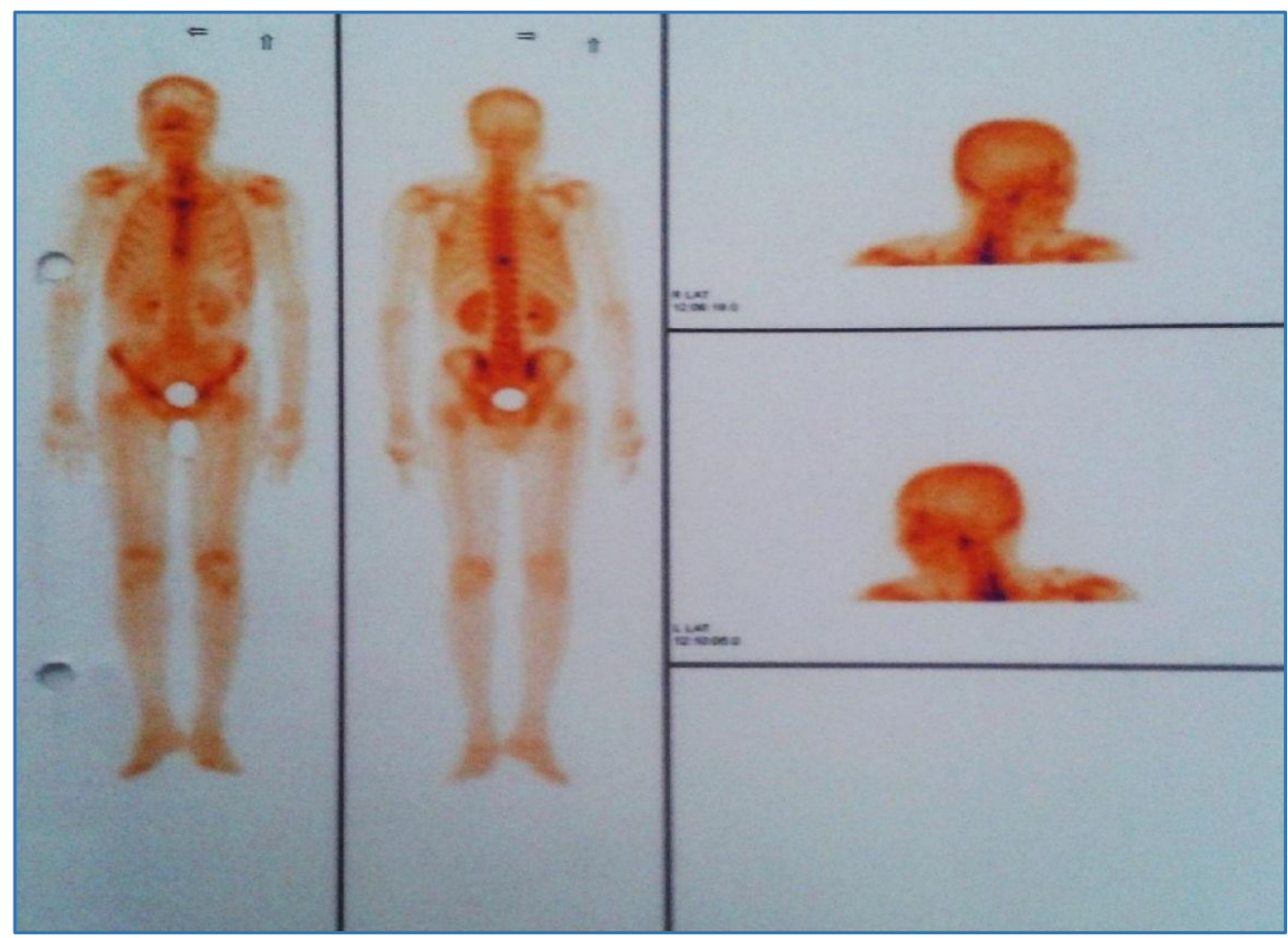

Fig. 3: Bone scan showing Metastasis to Vertebrae

Bone biopsy confirmed the metastasis. Patient was started on 6 cycles of Dacarbazine $200 \mathrm{mg} / \mathrm{m}^{2}$ (4 days of each cycle) with 28 days interval.

\section{DISCUSSION}

Melanoma is considered to be one of the rarest malignancy of oral cavity with an actual incidence of $0.2-8 \%$ of all melanomas.[2,3] The etiology is unknown as there are no consistent predisposing factors, although repeated irritation from ill-fitting dentures and tobacco consumption have been described.[7] Majority of the oral melanomas arise de novo. Alterations in the p53 gene have been identified in $66 \%$ of the cases of oral melanoma. ${ }^{[8]}$ In their initial stages, the disease is painless. Pigmented growth or swelling is the presenting complaint. As the disease progresses it presents with ulceration, growth or bleeding. Pain is a later manifestation. Satellite foci may surround the tumour.[9]

Grossly oral melanomas are usually flat with varying thickness. The tumour is uniformly brown or bluish black, although it can present as grey, purple or in red shades. ${ }^{[9]}$ In an amelanotic melanoma, the pigment is absent. It consists of an initial phase that is characterised by radial growth followed by a vertical growth phase that includes invasion of underlying tissue.[10] Westbury described a clinical classification, which includes: 1- Presence of only primary tumour, 2- Presence of metastasis which includes, 2a- Involvement of adjacent skin, $2 \mathrm{~b}$ - Involvement of adjacent lymph nodes, 2ab- Involvement of both adjacent skin and lymph nodes.[11] On microscopy, melanoma presents with giant epithelioid cells that are tightly packed with eosinophilic cytoplasm. Melanin pigment may be 
present or absent.[9] Histologically, oral melanoma can be graded by TNM staging which consists of.[12]

a) Stage I-Primary tumour present only (Tany N0M0). It is again subdivided into 3 levels: Level I: Pure in situ melanoma without evidence of invasion or in situ melanoma with microinvasion. Level II: Invasion up to the lamina propria. Level III: Deep skeletal tissue invasion into skeletal muscle, bone or cartilage. b) Stage II: Tumour metastatic to regional lymph nodes (Tany N1M0). c) Stage III: Tumour metastatic to distant sites (Tany Nany M1). From small lesions an excisional biopsy with a $1-2 \mathrm{~mm}$ margin is preferred. In case of larger lesions an incisional biopsy through the thickest part of the tumour is required. The tumour can be diagnosed with Hematoxylin and Eosin stains. If pigment is completely absent, immunohistochemical stains with markers like S-100 proteins and HMB-45 are used.[12] Lymph node metastasis reduces the mean survival time from four to less than 2 years. Liu et al. proposed that thickness of the tumour, cervical lymph node metastasis, presence or absence of ulceration and the anatomic sites are all independent risk factors.[13] Differential diagnosis includes physiologic pigmentation, nevi, oral melanotic macules, Kaposi's sarcoma, oral melanoacanthoma and amalgam tattoos.

Radical resection of the primary tumour along with neck dissection is the treatment of choice.[14] followed by initiation of an adjuvant chemotherapy with Dacarbazine (DTIC), Nimustine (ACNU) or Vincristine (VCR). On the other hand, patients who had underwent preoperative surgical procedures such as incisional biopsy or tooth extraction present rapidly with a distant metastasis and can be fatal. After primary therapy tumour may recur even after 10 to 15 years later. Distant metastasis to the lungs, brain, liver and bones are seen.

Many combination chemotherapies were proposed of which none of them showed significant difference compared to a single agent DTIC.[15]

Oral melanoma carries a poor prognosis. Rich vascular supply of the oral mucosa may allow invasion of the blood vessels and an early haematogenous dissemination making the tumour more aggressive.[15] Polymorphous tumour morphology, presence of vascular invasion, tumour thickness $>5 \mathrm{~mm}$ and necrosis may indicate poor survival rate in patients with primary melanomas of head and neck region.

\section{CONCLUSION}

Oral cavity is a common site for pigmented lesions. In case of doubtful pigmented lesions, an early biopsy may be considered for diagnosis. Early identification of the tumour and treatment by surgery followed by adjuvant chemotherapy may lead to a better prognosis.

\section{REFERENCES}

1. Ardekian L, Rosen DJ, Peled M, et al. Primary gingival malignant melanoma. Report of 3 cases. J Periodontol 2000;71(1):117-20.

2. Patton LL, Brahim JS, Baker AR. Metastatic malignant melanoma of the oral cavity. A retrospective study. Oral Surg Oral Med Oral Pathol 1994;78:51-6.

3. Regezi JA, Sciubba J. Oral Pathology. 2nd edn. Philadelphia: WB Saunders, 1993;165-71.

4. Delgado Azañero WA, Mosqueda Taylor A. A practical method for clinical diagnosis of oral mucosal melanomas. Med Oral 2003;8:348-52.

5. Manganaro AM, Hammond HL, Dalton MJ, et al. Oral melanoma: case reports and review of the literature. Oral Surg Oral Med Oral Pathol Oral Radiol Endod. 1995;80:670-6.

6. Greene GW, Haynes JW, Dozier M, et al. Primary malignant melanoma of oral mucosa. Oral Surg Oral Med Oral Pathol 1953;6:1435-43.

7. Rapidis AD, Apostolidis C, Vilos G, et al. Primary malignant melanoma of the oral mucosa. J Oral Maxillofac Surg 61 (2003), pp. 1132-1139.

8. Prasad ML, Jungbluth AA, Patel SG, et al. Expression and significance of cancer testis antigens in primary mucosal melanoma of the head and neck. Head Neck 2004;26:1053-7.

9. Berthelson A, Andersen AP, Jensen TS, et al. Melanomas of mucosa in the oral cavity and upper respiratory passages. Cancer 1984;54:907-12.

10. Lopez-Graniel CM, Ochoa-Carrillo FJ and Meneses-García A. "Malignant melanoma of the oral cavity: diagnosis and treatment experience in a Mexican population." Oral Oncology, vol. 35, no. 4, pp. 425-430, 1999.

11. Westbury G. Malignant melanoma of skin. In: Lumley J, Cravin J, editors. Surgical Review. vol. 1. London: Pitman Medical; 1979. pp. 24-36.

12. Meleti M, René Leemans C, Mooi WJ, et al. “Oral malignant melanoma: a review of the literature." Oral Oncology, vol. 43, no. 2, pp. 116-121, 2007.

13. Aguas SC, Quarracino MC, Lence AN, et al. Primary melanoma of the oral cavity: ten cases and review of 177 cases from literature. Med Oral Patol Oral Cir Bucal 2009;14:265-71.

14. Lengyel E, Glide K, Remenar E, et al. Malignant mucosal melanoma of the head and neck. Pathol Oncol Res 2003;9:7-12.

15. Chapman PB, Einhorn LH, Meyers ML, et al. 1999. Phase III multicenter randomized trial of the Dartmouth regimen versus dacarbazine in patients with metastatic melanoma. J Clin Oncol 17:2745-2751. 